\title{
Propriedades Mecânicas do Músculo \\ Gastrocnêmio de Ratas, Imobilizado e \\ Posteriormente Submetido a Diferentes \\ Protocolos de Alongamento
}

\author{
Mechanical Properties of Gastrocnemius Muscle of Female \\ Rats Immobilized and Posteriorly Submitted to Different \\ Stretching Protocols
}

Juliana Cristina Polizello

Leonardo César Carvalho

Fernando Cassiolato Freitas

Natália Padula

Antonio Carlos Shimano

Ana Claudia Mattiello-Sverzut

Departamento de Biomecânica,

Medicina e Reabilitação do

Aparelho Locomotor da Faculdade de Medicina de Ribeirão Preto da

Universidade de São Paulo.

\section{Endereço para correspondência:}

Profa. Dra. Ana Cláudia Mattiello-

Sverzut

Departamento de Biomecânica,

Medicina e Reabilitação do

Aparelho Locomotor

Faculdade de Medicina de Ribeirão Preto, USP

Av. Bandeirantes, 3.900. Monte Alegre 14048-900 - Ribeirão Preto, SP

E-mail: acms@fmrp.usp.br

Submetido em 10/03/2008 Versão final recebida em 21/07/2008 Aceito em 24/10/2008

\section{RESUMO}

O alongamento é amplamente utilizado na prática clínica da fisioterapia e no desporto, porém, as alterações mecânicas que essa técnica gera no músculo esquelético são pouco exploradas cientificamente. Este estudo avaliou as alterações mecânicas que acometem o músculo gastrocnêmio de ratas Wistar, adultas jovens, após 14 dias de imobilização e, secundariamente, submetido a alongamento manual passivo por 10 dias consecutivos, aplicado uma ou duas vezes ao dia. Foram utilizados 50 animais, sendo 10 para cada grupo: Controle (GC); Imobilizado (Gl); Imobilizado e Liberado (GIL); Imobilizado e alongado uma vez ao dia (GIA1); e Imobilizado e alongado duas vezes ao dia (GIA2). O músculo gastrocnêmio foi submetido ao ensaio mecânico de tração, onde foram avaliadas as propriedades de carga e alongamento nos limites máximo e proporcional, além de rigidez e resiliência. A imobilização reduziu os valores das propriedades mecânicas de carga no limite máximo (CLM), carga no limite proporcional (CLP), alongamento no limite máximo (ALM), rigidez e resiliência, em 44,4\%, 34,4\%, 27,6\%,64,4\% e 54\%, respectivamente, quando comparados com os valores do GC. A remobilização livre e o alongamento restauraram as propriedades de CLM, CLP, ALM, rigidez e resiliência do músculo, exceto para o GIA2, que foi incapaz de restabelecer a propriedade de ALM (31,3\% menor que GC). Concluí-se, portanto que, após 14 dias de imobilização segmentar, cargas individuais de alongamento e a livre movimentação permitem restituir as propriedades mecânicas do tecido muscular.

Palavras-chave: imobilização, músculo esquelético, estresse mecânico, exercício.

\section{ABSTRACT}

Stretching is widely employed in physiotherapeutic clinical practice and in sportive activities; however, the mechanical alterations of the skeletal muscle generated by this technique are poorly scientifically investigated. This study evaluated the mechanical alterations suffered by the gastrocnemius muscle of young adult female Wistar rats, submitted to 14 days of immobilization followed by passive manual stretching during 10 consecutive days once or twice a day. Fifty animals were equally distributed in five groups, Control (CG); Immobilized (IG); Immobilized and liberated (ILG); Immobilized and submitted to stretching once a day (IEG1); Immobilized and submitted to stretching twice a day (IEG2). The gastrocnemius muscle was analyzed by mechanical traction assay and the properties related to load and maximal and proportional stretching evaluated in addition to stiffness and resilience. Immobilization decreased load at maximal thresholds (MTL), load at proportional thresholds (LPT), stretch at maximal thresholds (SMT), stiffness and resilience were reduced in $44.4 \%, 34.4 \%, 27.6 \%, 64.4 \%$ and $54 \%$ respectively, compared to CG values. With subsequent free remobilization and stretching, all parameters were restored except for IEG2 in which SMT remained reduced in 31.3\%, when compared to CG. It is concluded that after 14 days of segmental immobilization, individual stretching loads and free movements contribute to regain muscle mechanical properties.

Keywords: immobilization, skeletal muscle, mechanical stress, exercise. 


\section{INTRODUÇÃO}

O alongamento muscular é um recurso utilizado com frequência na prática clínica da fisioterapia e é indicado quando a amplitude de movimento está limitada, comprometendo o desempenho funcional ${ }^{(1)}$.

Os benefícios da utilização do alongamento passivo como protocolo terapêutico se respaldam em estudos que descrevem aumento macroscópico da amplitude de movimento articular ${ }^{(2-4)}$ e alterações morfofuncionais, como adição de sarcômeros longitudinalmente às miofibrilas ${ }^{(2,5)}$, além de alterações estruturais envolvendo elementos passivos da fibra muscular, paralelos aos elementos contráteis ${ }^{(6)}$, como fibras de colágeno ${ }^{(7)}$, titina ${ }^{(8)}$ e proteínas do $\operatorname{costâmeros}^{(9,10)}$. As alterações supracitadas, por sua vez, influenciam diretamente as propriedades mecânicas do tecido muscular ${ }^{(11,12)}$.

Em situações de imobilização e desuso, podem ser observadas atrofia das fibras, diminuição da capacidade de gerar força, redução da extensibilidade, da velocidade de contração e da resistência muscular, resultando em aumento do tecido conjuntivo intramuscular ${ }^{(13)}$. As primeiras investigações de propriedades mecânicas identificaram redução significativa da tensão máxima desenvolvida pelo músculo testado, após imobilização do membro posterior de ratos em posição de encurtamento ${ }^{(14)}$. Estudos utilizando a imobilização gessada aplicada ao membro posterior de ratas demonstraram reduções significativas nos valores das propriedades mecânicas de rigidez, carga e alongamento nos limites máximo e de proporcionalidade ${ }^{(15)}$. A eleição do protocolo de reabilitação deve ser cautelosa, visto que, depois de determinado período de imobilização, as propriedades mecânicas pertinentes ao limite elástico e plástico estão reduzidas, deixando o músculo suscetível a lesões ${ }^{(16)}$.

Apesar de protocolos de alongamento serem comuns na prática clínica, diferentes são os questionamentos sobre como os programas de alongamento influenciam nas propriedades elásticas passivas da musculatura esquelética(3). Em outras palavras, a complacência muscular mensurada através das propriedades mecânicas ainda apresenta variáveis pouco exploradas pela literatura científica e, ainda, mediante a análise das diversas variáveis morfofuncionais que influenciam o tecido muscular esquelético, não existe consenso quanto à frequência, ao tempo e ao número de séries que um programa de alongamento muscular deve conter ${ }^{(2,16)}$. Sendo assim, o presente estudo buscou mensurar as possíveis alterações das propriedades mecânicas do músculo gastrocnêmio de ratas, induzidas pela imobilização, comparando-as com alongamento passivo, aplicado uma e duas vezes ao dia, em animais adultos.

\section{MÉTODOS}

\section{Animais}

Foram utilizadas 50 ratas (Rattus norvegicus albinus) da variedade Wistar, adultas jovens, com massa corporal média de $200 \pm 30 \mathrm{~g}$, fornecidas pelo Biotério Central da Prefeitura do Campus de Ribeirão Preto, da Universidade de São Paulo (USP). O projeto foi aprovado pela Comissão de Ética no Uso de Animais (CEUA) - Universidade de São Paulo - Campus Ribeirão Preto-SP (Protocolo n 06.1.692.53.8). Os animais foram mantidos em gaiolas plásticas, separados em número de dois, onde permaneceram em temperatura ambiente controlada $\left(24^{\circ} \mathrm{C}\right)$, com livre acesso à alimentação padrão e água ad libitum, no Biotério do Laboratório de Bioengenharia da Faculdade de Medicina de Ribeirão Preto-USP.

\section{Grupos experimentais}

Os animais (total $=50$ ) foram divididos em cinco grupos, sendo eles: Controle (GC), mantidos alojados em gaiola plástica por um período de 14 dias, a fim de acompanhar o período de contenção dos animais dos demais grupos; Imobilizado (GI), permaneceram com o membro posterior direito imobilizado por 14 dias consecutivos; Imobilizado e liberado (GIL), ficaram com a imobilização do membro posterior direito por 14 dias e foram liberados por 10 dias; Imobilizado e alongado 1 (GIA1), cujos animais tiveram o membro posterior direito imobilizado por 14 dias e, posteriormente, foram submetidos à técnica de alongamento passivo manual uma vez ao dia; Imobilizado e alongado 2 (GIA2), cujos animais tiveram o membro posterior direito imobilizado por 14 dias e foram submetidos ao mesmo protocolo de alongamento passivo manual, aplicado duas vezes ao dia.

\section{Imobilização}

A imobilização do membro posterior direito dos animais foi realizada após aplicação de anestésico intramuscular, sendo elaborado um aparelho gessado que incluía a pelve, quadril, joelho em total extensão e tornozelo em flexão plantar máxima, semelhante à imobilização adotada por Carvalho et al. ${ }^{(11)}$. Os animais foram mantidos imobilizados por 14 dias consecutivos.

\section{Alongamento passivo manual}

A técnica de alongamento manual passivo foi adotada seguindo a descrita por Mattiello-Sverzut et al. ${ }^{(26)}$. Com a articulação do joelho mantida em extensão completa, dois sujeitos treinados executaram força manual (não quantificada) que, aplicada na porção plantar da pata posterior direita, produzia o movimento de dorsiflexão da articulação do tornozelo, gerando o alongamento passivo do músculo gastrocnêmio das ratas, respeitando o limite articular. Essa técnica buscou mimetizar a prática terapêutica clínica ${ }^{(30)}$. Para tanto, utilizouse uma série de 10 exercícios, de 30 segundos cada, com intervalos de 30 segundos, por 10 dias consecutivos, aplicando uma ou duas vezes ao dia. No grupo cujo protocolo adotado foi a prática diária única, a técnica de alongamento foi realizada no período da manhã. Para o grupo submetido ao protocolo aplicado duas vezes ao dia, foi realizada em períodos distintos, sendo uma aplicação pela manhã e outra ao final da tarde.

Após as intervenções, os animais foram submetidos à eutanásia por meio de uma dose excessiva de cloridrato de ketamina $(80 \mathrm{mg} / \mathrm{kg}$ ) e cloridrato de xilazina $(15 \mathrm{mg} / \mathrm{kg}$ ) via intraperitoneal, seguindo os princípios éticos em pesquisa animal. Em seguida, tiveram o músculo gastrocnêmio direito dissecado, mantendo as inserções no fêmur e no calcâneo, o que permitiu a fixação do músculo à máquina universal de ensaios mecânicos de tração longitudinal. Até o momento de realização do ensaio, o músculo gastrocnêmio foi mantido em uma solução fisiológica a 0,9\% de cloreto de sódio $(\mathrm{NaCl})$, à temperatura de $25^{\circ} \mathrm{C}$.

\section{Ensaio de tração}

Os ensaios mecânicos de tração dos músculos gastrocnêmio das ratas foram realizados seguindo protocolo aplicado por Carvalho et al. ${ }^{(11)}$, em uma máquina universal de ensaios modelo DL10000 (EMIC - São José dos Pinhais-PR - Brasil), equipada com uma célula de carga 50kgf, pertencente ao Laboratório de Bioengenharia da Faculdade de Medicina de Ribeirão Preto-USP. A máquina universal de ensaios está conectada a um microcomputador equipado com um software capaz de captar os valores de carga e alongamento dos músculos durante a execução dos procedimentos.

Os parâmetros mecânicos avaliados após o ensaio dos músculos foram obtidos a partir do gráfico carga versus alongamento, obtido diretamente do programa TESC (São Paulo-SP - Brasil), onde é possível identificar as amplitudes plástica e elástica do material submetido à deformação. 
Dentre as propriedades avaliadas neste estudo estão: alongamento no limite de proporcionalidade (ALP), que é o valor de alongamento representado no limite elástico $\left(\times 10^{-3} \mathrm{~m}\right)$; carga no limite de proporcionalidade (CLP), cujo valor identifica a carga registrada no limite elástico (N); alongamento no limite máximo (ALM), que é o valor de alongamento no ponto de maior carga na fase plástica $\left(\times 10^{-3} \mathrm{~m}\right)$; carga no limite máximo (CLM), que representa o maior valor de carga registrado na fase plástica (N); rigidez, que corresponde à resistência passiva do músculo, é representada em newtons/metro ( $\mathrm{N} / \mathrm{m})$; resiliência, que representa a capacidade de absorver energia na fase elástica do músculo, expressa em newtons $x$ metro (N.m).

\section{Análise estatística}

Os resultados tiveram a normalidade testada utilizando o método de Kolmogorov e Smirnov. Posteriormente, foi utilizado o teste ANOVA para análise dos fatores, seguida do teste post-hoc de comparações múltiplas de Tukey-Kramer para verificar as diferenças entre os grupos. Em todas as comparações foi adotado nível de significância $p<0,05$. 0 tratamento dos dados foi realizado com auxílio do software SPSS 7.5.1.

\section{RESULTADOS}

A imobilização do músculo gastrocnêmio reduziu significativamente as propriedades de CLM (GI vs. GC, $p<0,01$; figura 1A) e ALM (GI vs. GC, $p<0,001$; figura 1B), CLP (GI vs. $G C, p<0,05$; figura $1 C$ ), rigidez ( $G \mid$ vs. $G C, p<0,01$; figura 1E) e resiliência ( $G$ l vs. $G C, p<0,05$; figura $1 F$ ), quando comparado com o GC. ALP não apresentou variação estatística significativa na comparação entre os grupos. Considerando as demais propriedades, os animais do Gl apresentaram valores inferiores em relação aos demais grupos em todas elas, com exceção do protocolo de alongamento aplicado duas vezes ao dia, que teve valor de ALM menor que aqueles observados no Gl (GIA2 vs. Gl, $p=n s$; figura 1B).

A remobilização livre, assim como o alongamento aplicado uma vez ao dia, foi capaz de devolver ao músculo imobilizado as propriedades de CLM (GIL vs. Gl, $p<0,001$ e GIA1 vs. Gl, $p<0,001$; figura 1A), CLP (GIL vs. $G$ l, $p<0,001$ e GIA1 vs. Gl, $p<0,001$; figura 1C), rigidez (GIL vs. $G$ l, $p<0,001$ e GIA1 vs. Gl, $p<0,001$; figura 1E) e resiliência (GIL vs. Gl, $p<0,05$ e GIA1 vs. Gl, $p<0,05$; figura 1F).

$\mathrm{O}$ alongamento realizado duas vezes ao dia apresentou melhora significativa dos valores de CLM (GIA2 vs. GI, $p<0,001$; figura 1A), CLP (GIA2 vs. Gl, $p<0,001$; figura $1 C$ ) e rigidez (GIA2 vs. $G$ l, $p<0,001$; figura 1E), quando comparado com o Gl. Porém, os valores obtidos na propriedade de ALM não alcançaram os valores do GC (GIA2 vs. GC, $p<0,001$; figura 1B). Além disso, o alongamento muscular passivo aplicado duas vezes ao dia proporcionou valores de ALM (GIA2 vs. GIA1, $p<0,05$; figura $1 B$ ) significativamente menores que os obtidos pelos animais do GIA1.

\section{DISCUSSÃO}

Este estudo buscou avaliar os efeitos da técnica de alongamento passivo aplicada uma e duas vezes ao dia sobre as propriedades mecânicas do músculo gastrocnêmio após imobilização segmentar. A avaliação dessas propriedades mecânicas no músculo esquelético fornece informações relevantes para o entendimento dos mecanismos adaptativos frente a diferentes estímulos externos, como imobilização e/ou alongamento ${ }^{(17,18)}$.

Os dados obtidos no grupo de animais submetidos à imobilização mostraram redução importante dos valores das propriedades mecânicas referentes às fases plástica e elástica em relação aos demais grupos. Essa redução pode ser explicada por: (1) alteração na organização das fibras de colágeno - estudo científico desenvolvido por Järvinen et al.(19) demonstraram aumento no volume de tecido conjuntivo intramuscular em músculos esqueléticos submetidos à imobilização em posição de encurtamento. Os autores observaram ainda alterações nas características estruturais das fibras de colágeno, como maior quantidade de ligações perpendiculares entre as fibras, fibras mais estreitas, numerosas e menos resistentes à tensão. Um estudo conduzido por Coutinho et al. (20) identificou ainda que imobilização por quatro semanas originou redução significativa na birrefringência das fibras de colágeno, indicando desorganização e redução na agregação dos feixes de colágeno; (2) atrofia das fibras musculares - sabe-se que em situações de desuso ocorre desequilíbrio entre síntese e degradação proteica, resultando em redução do conteúdo de proteínas miofibrilares ${ }^{(13,18)}$. Essa perda proteica, por sua vez, acarreta redução do volume muscular(21), diminuição da força de contração(13) e redução no número de sarcômeros em série, quando o músculo se mantém em posições de encurtamento(18,21).

Essas alterações estão diretamente relacionadas à redução na capacidade de deformação, que gera menor capacidade do músculo em se alongar no limite máximo, além de reduzir a rigidez e a resiliência, o que justificaria os achados do Gl deste e de outros estudos que obtiveram resultados semelhantes ${ }^{(11,17)}$.

No entanto, algumas dessas alterações podem ser prevenidas ou mesmo revertidas com a utilização de técnicas de reabilitação como alongamento passivo manual. Como já destacado previamente, essa técnica gera no músculo um estímulo tensional capaz de promover mudanças morfológicas ${ }^{(5,16)}$ e mecânicas $\left.2,19,20\right)$.

Neste estudo, o protocolo de alongamento passivo aplicado uma vez ao dia foi capaz de devolver ao músculo as propriedades de carga nos limites proporcional e máximo, resiliência e rigidez, reduzidas pelo processo de imobilização. As justificativas para esse fato podem estar relacionadas com (A) aumento no comprimento muscular, (B) reorganização do tecido conjuntivo intramuscular e/ou, (C) deformação de proteínas estruturais da fibra muscular.

Com relação ao aumento no comprimento muscular (A), estudos experimentais que aplicaram alongamento passivo no músculo esquelético de animais demonstraram aumento significativo do número de sarcômeros em série ${ }^{(5,16)}$. Estudos que aplicaram técnica de alongamento em humanos ${ }^{(2,3)}$ identificaram aumento significativo da amplitude de movimento, podendo estar relacionado, não apenas com o aumento de sarcômeros em série, mas também com a tolerância a esse exercício. Esses estudos relataram aumento na flexibilidade muscular, o que justifica a capacidade do músculo de suportar maior carga e permitir maior alongamento e, consequentemente, melhorar as propriedades de rigidez e resiliência, encontrado no GIA1 deste estudo.

Para reorganização do tecido conjuntivo intramuscular (B), programas de alongamento passivo demonstraram aumento da extensibilidade muscular devido à reorganização do tecido conjuntivo intramuscular ${ }^{(20,24)}$. O aumento do comprimento muscular altera a relação entre as fibras de colágeno e as fibras musculares, permitindo maior resistência ao torque passivo, principalmente próximo do alongamento máximo(3), o que corrobora a melhora na propriedade de carga no alongamento máximo.

E, finalmente, considerando deformação de proteínas estruturais da fibra muscular (C), durante o ensaio mecânico, a força de resistência à tração muscular está diretamente associada à titina, uma proteína estrutural do sarcômero que auxilia na resistência passiva natural do músculo esquelético(8). Durante o alongamento muscular, a titina altera sua configuração de acordo com a variação do tipo de fibra, modulando sua resistência e elasticidade conforme a função da fibra muscular ${ }^{(3,23)}$. Dessa forma, o alongamento passivo é capaz de alterar as propriedades mecânicas musculares, pois induz alterações na titina e esta, por sua vez, reduz a resistência passiva e aumenta a viscoelasticidade tecidual ${ }^{(12,24)}$. 

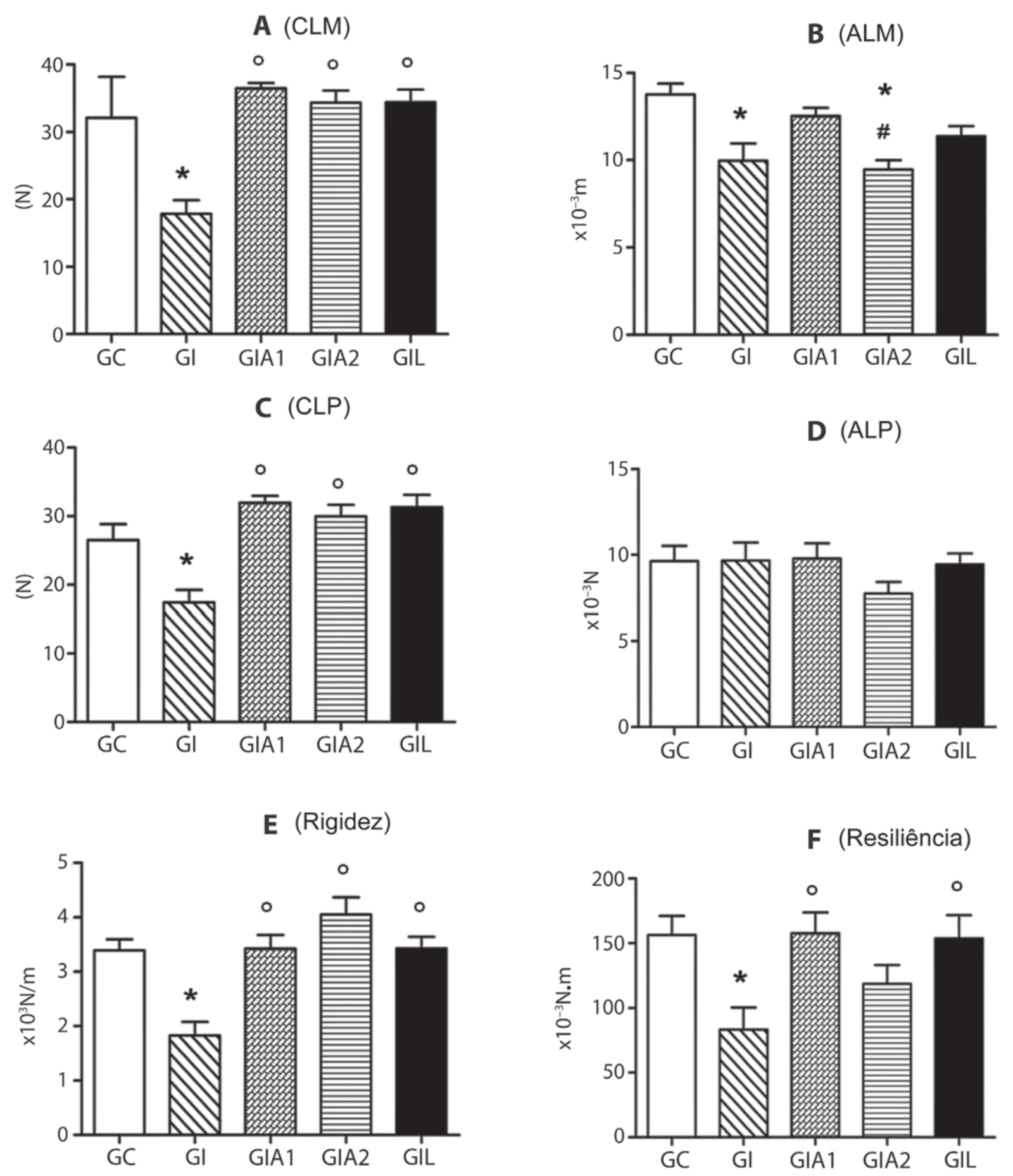

Figura 1. Valores de média e desvio padrão referentes às propriedades mecânicas dos grupos Controle (GC), Imobilizado (GI), Imobilizado e liberado (GIL), Imobilizado e submetido ao alongamento uma vez ao dia (GIA1) e Imobilizado e submetido ao alongamento duas vezes ao dia (GIA2). A: Propriedade de carga no limite máximo (CLM): B: Propriedade de alongamento no limite máximo (ALM); C: Propriedade de carga no limite proporcional (CLP); D: Propriedade de alongamento no limite proporcional (ALP); E: propriedade de rigidez; F: propriedade de resiliência. * $p<0,05$ comparado com GC; ${ }^{\circ} p<0,05$ comparado com Gl; $\#<0,05$ comparado com GIA1

Os resultados apontam ainda que os animais do GIL apresentaram achados similares aos do GIA1, o que sugere que a liberação após o período de imobilização permite retorno às atividades normais de movimentação do membro e, consequentemente, reestruturação funcional do gastrocnêmio, que pode obedecer às justificativas aqui apontadas. Sendo assim, a postura de alongamento do músculo gastrocnêmio, adotada pelos animais em posição de repouso, gera um estímulo tensional com resposta semelhante à do alongamento muscular aplicado uma vez ao dia. Järvinen et al. ${ }^{(25)}$ não encontraram diferença significativa na porcentagem de tecido conectivo intramuscular de músculos de animais liberados pós-imobilização quando comparados com aqueles de animais treinados em esteira, sugerindo que ambas as atividades foram capazes de restaurar os valores às condições controle. Por outro lado, Mattiello-Sverzut et al. (26), seguindo protocolo de imobilização e alongamento similar ao aqui aplicado, encontraram aumento significativo na quantidade de tecido conjuntivo de músculo sóleo de animais alongados (10 séries de 15 segundos) pós-imobilização quando comparados com o de animais liberados. Talvez um estímulo 
agudo e menos duradouro como a duração da manobra em 15 segundos favoreça a síntese de tecido conjuntivo perimisial em maior intensidade que a manobra de 30 segundos, utilizada no presente estudo. Outra justificativa pode residir nos diferentes tipos de fibras que predominam nos músculos confrontados dos diferentes estudos: gastrocnêmio (predomínio de fibra tipo II) e sóleo (predomínio de fibra tipo I), respectivamente.

Além disso, a duração e a frequência do alongamento podem ter influenciado algumas alterações do tecido muscular. Os resultados apontam que o GIA2 teve comportamento semelhante ao do GIA1 para as propriedades de CLM, CLP, ALP, rigidez e resiliência, porém foi incapaz de recuperar os valores da propriedade de ALM, comprometendo a fase plástica do alongamento e, portanto, demonstrando que o músculo pode tornar-se suscetível a ruptura precoce ${ }^{(17)}$. Análise histomorfológica dos músculos gastrocnêmio e sóleo dos animais submetidos ao alongamento muscular uma e duas vezes ao dia, após 14 dias de imobilização, tem apontado aumento na incidência de alterações do tipo degenerativo/necrótico para o grupo GIA2 (dados não publicados). De acordo com os estudos de Gomes et al.(16), durante o período de imobilização o protocolo de alongamento realizado a cada três dias determinou maior incidência de lesão celular que quando aplicado a cada sete dias. Suscitamos, portanto, a hipótese de que o alongamento aplicado duas vezes ao dia pode ter causado alterações degenerativas mais intensas nas fibras musculares. Durante essa manobra, é possível que as proteínas do costâmero tenham perdido sua continuidade. Designa-se costâmero uma associação de proteínas subsarcolemais que agregam mecanicamente a unidade contrátil do músculo à membrana plasmática, contribuindo amplamente na manutenção da integridade do sarcolema ${ }^{(9,10)}$. Associado a esse rompimento da membrana plasmática o processo de degeneração celular pode ter sido evocado pela cascata de eventos que envolvem proteólise lisosomal via catepsina e proteasomo ubiquitina ATP-dependente ${ }^{(27,28)}$. Além disso, alterações da merosina - uma proteína da matriz extracelular responsável pela união entre proteínas da membrana e colágeno - provocam desarranjo na transmissão da força muscular entre o sarcolema e a fibras de colágeno, gerando anomalias na capacidade viscosa do músculo em resposta às cargas mecânicas ${ }^{(29)}$.

\section{CONCLUSÃO}

Subsidiados pelos dados das propriedades mecânicas pertencentes às fases elástica e plástica, obtidos nesse estudo, frente à deformação do músculo gastrocnêmio após um período de imobilização por 14 dias, concluímos que o protocolo de alongamento aplicado uma vez ao dia e a livre movimentação produziram melhores resultados no músculo de ratas que o protocolo aplicado duas vezes ao dia.

\section{AGRADECIMENTOS}

Aos funcionários do Laboratório de Bioengenharia da FMRP-USP e à Faepa - Fundação de Apoio ao Ensino, Pesquisa e Assistência do Hospital das Clínicas de Ribeirão Preto.

Todos os autores declararam não haver qualquer potencial conflito de interesses referente a este artigo.

\section{REFERÊNCIAS BIBLIOGRÁFICAS}

1. De Deyne, PG. Application of passive stretch and its implications for muscle fibers. Phys Ther 2001;81:819-27.

2. Whatman $C$, Knappstein A, Hume P. Acute changes in passive stiffness and range of motion poststretching. Physical Therapy in Sport 2006;7:195-200.

3. Gajdosik RL, Allred JD, Gabbert HL, Sonsteng BA. A stretching program increases the dynamic passive length and passive resistive properties of the calf muscle-tendon unit of unconditioned younger women. Eur J Appl Physiol 2007;99:449-54.

4. Beedle BB, Mann CL. No difference in pre- and postexercise stretching on flexibility. J Strength Cond Res 2007;21:780-3.

5. Coutinho EL, Gomes AR, França CN, Oishi J, Salvini TF. Effect of passive stretching on the immobilized soleus muscle fiber morphology. Braz J Med Biol Res 2004;37:1853-61.

6. Herzog W, Schachar R, Leonard TR. Characterization of the passive component of force enhancement following active stretching of skeletal muscle. J Exp Biol 2003;206:3635-43.

7. Kjær M, Magnusson P, Krogsgaard M, Møller JB, Olesen J, Heinemeier K, et al. Extracellular matrix adaptation of tendon and skeletal muscle to exercise. J Anat 2006;208:445-50.

8. Herzog W. Force enhancement following stretch of activated muscle: critical review and proposal for mechanisms. Med Biol Eng Comput 2005;43:173-80.

9. Rybakova IN, Patel JR, Ervasti JM. The dystrophin domplex forms a mechanically strong link between the sarcolemma and costameric actin, J Cell Biol 2000;150:1209-14.

10. Ervasti, JM. Costameres: the Achilles' heel of Herculean muscle. J Biol Chem 2003;278:13591-4.

11. Carvalho CMM, Shimano AC, Volpon JB. Efeitos da imobilização e do exercício físico em algumas propriedades mecânicas do músculo esquelético. Rev Bras Eng Bio 2002;18:65-73.

12. Weir E, Tingley J, Elder GCB. Acute passive stretching alters the mechanical properties of human plantar flexors and the optimal angle for maximal voluntary contraction. Eur J Appl Physiol 2005;93:614-23.

13. Frimel TN, Kapadia F, Gaidosh GS, Li Y, Walter GA, Vandenborne K. A model of muscle atrophy using cast immobilization in mice. Muscle Nerve 2005;32:672-4.

14. Williams PE, Goldspink G. Changes in sarcomere length and physiological properties in immobilized muscle. J Anat 1987;127:459-68.

15. Järvinen MJ, Einola SA, Virtanen EO. Effect of the position of immobilization upon the tensile properties of the rat gastrocnemius muscle. Arch Phys Med Rehabil 1992;73:253-7.

16. Gomes ARS, Cornachione A, Salvini TF, Mattiello-Sverzut AC. Morphological effects of two protocols of passive stretch over the immobilized rat soleus muscle. J Anat 2007;210:328-35.
17. Matheus JPC, Oliveira JGP, Gomide LB, Volpon JB, Shimano AC. Efeitos da estimulação elétrica neuromuscular durante a imobilização nas propriedades mecânicas do músculo esquelético. Rev Bras Med Esporte 2007;13:1-5.

18. Aquino CF, Viana SO. Fonseca ST. Comportamento biomecânico e resposta dos tecidos biológicos ao estresse e à imobilização. Fisioterapia em Movimento 2005;18:35-43.

19. Järvinen TAH, Jozsa L, Kannus P, Jarvinen TLN, Jarvinen M. Organization and distribution of intramuscular connective tissue in normal and immobilized skeletal muscles. J Muscle Res Cell Motil 2002;23:245-54

20. Coutinho EL, DeLuca C, Salvini TF, Vidal BC. Bouts of Passive Stretching after Immobilization of the Rat Soleus Muscle Increase Collagen Macromolecular Organization and Muscle Fiber Area. Connect Tissue Res 2006;47:278-86.

21. Da Silva CA, Guirro R, Polacow M, Cancelliero K, Durigan J. Rat hindlimb joint immobilization with acrylic resin orthoses. Braz J Med Biol Res 2006;39:979-85.

22. Kjær M. Role of Extracellular Matrix in Adaptation of Tendon and Skeletal Muscle to Mechanical Loading. Physiol Rev 2004;84:649-98.

23. Mutungi G, Ranatunga KW. The viscous, viscoelastic and elastic characteristics of resting fast and slow mammalian (rat) muscle fibres. J Physiol 1996;496:827-36.

24. Proske U, Morgan DL. Do cross-bridges contribute to the tension during stretch of passive muscle? J Muscle Res Cell Motil 1999;20:433-42.

25. Järvinen TAH, Józsa L, Kannus $P$, Järvinen TLN, Hurme T, Kvist M, et al. Mechanical loading regulates the expression of tenascin- $C$ in the myotendinous junction and tendon but does not induce de novo synthesis in the skeletal muscle. J Cell Sci 2003;116:857-66.

26. Mattiello-Sverzut AC, Carvalho LC, Cornachione A, Nagashima M, Neder L, Shimano AC. Morphological effects of electrical stimulation and intermittent muscle stretch after immobilization in soleus muscle. Histol Hitopathol 2006;21:957-64

27. Chopard A, Arrighi N, Carnino A, Marini JF. Changes in dysferlin, proteins from dystrophin glycoprotein complex, costameres, and cytoskeleton in human soleus and vastus lateralis muscles after a long-term bedrest with or without exercise. FASEB J 2005;19:1722-4.

28. Coffey VG, Hawley JÁ. The molecular bases of training adaptation. Sports Med 2007;37:737-63. 29. Jannapureddy SR, Patel SR, Hwang W, Boriek AM. Selected contributions: Merosin deficiency leads to alterations in passive and active skeletal muscle mechanics. J Appl Physiol 2003;94:2524-33. 30. Brandy WD, Irion, JM. The effect of time on static stretch on the flexibility of the hamstring muscle. Phys Ther 1994;74:845-50. 